\title{
Expresión de proteínas relacionadas con resistencia a múltiples drogas (MDR-Proteínas) en el cáncer de pulmón
}

\author{
A. Paredes Lario¹, C. Blanco García ${ }^{1}$, M. Echenique Elizondo²
}

\section{Resumen}

- Introducción: La reducción en la acumulación intracelular de los fármacos, es uno de los mecanismos más frecuentes de resistencia a los antineoplásicos. Las proteinas transportadoras de membrana juegan un papel esencial en este fenómeno.

- Material y métodos: Se recogieron 147 muestras tumorales procedentes de 143 pacientes. De éstas, 35 eran broncoscópicas y 112 quirúrgicas. Resultaron válidas para el estudio 101 muestras correspondientes a 99 pacientes. Las muestras tumorales criocongeladas fueron sometidas a análisis inmunohistoquímico para la detección de las tres MDR-proteínas, Pgp, Mrp1 y Lrp

- Resultados: No expresaban ninguna proteína, 16 casos. Expresaban una sola proteína, 32 casos: 3 Pgp, 11 Mrp1 y 18 Lrp=0. Expresaban dos proteínas, 34 casos: 24 Pgp y Lrp, 5 Mrp1 y Pgp, 5 Mrp1 y Lrp=0. Expresaban las tres proteínas, 17 casos. No hemos detectado relación significativa entre la edad y la expresión de $\operatorname{Pgp}(\mathrm{p}=0.74)$, Mrp1 ( $\mathrm{p}=0.95)$, o Lrp ( $\mathrm{p}=0.26)$. No detectamos diferencias significativas entre sexos, tanto al analizar por el número $(\mathrm{p}=0.72)$, como por el tipo $(\mathrm{p}=0.39)$ de proteínas expresadas de forma simultánea.Tampoco detectamos diferencias significativas entre los diferentes estadios tumorales, tanto para el número ( $\mathrm{p}=0.55)$, como para el tipo $(\mathrm{p}=0.21)$ de MDR-proteínas expresada. Tampoco detectamos diferencias significativas entre los diferentes grados histológicos, tanto para el número $(\mathrm{p}=0.59)$, como para el tipo $(\mathrm{p}=0.51)$ de MDR-proteínas expresadas simultáneamente esadas simultáneamente.

La tendencia de Pgp y Lrp a expresarse asociadas ha resultado muy significativa ( $\mathrm{p}<0.01)$, no ocurrió lo mismo para la asociación Pgp y Mrp1 (p=0.18) o Mrp1 y Lrp ( $\mathrm{p}=0.26)$.

- Conclusiones: El cáncer de pulmón expresa con frecuencia MDR-proteínas.De las tres MDR-proteínas estudiadas, Pgp Mrp1 y Lrp, es Lrp la más frecuentemente expresada. Los adenocarcinomas expresan menos Mrp1 que el resto de los tipos histológicos.Los carcinomas escamosos expresan menos Lrp que los adenocarcinomas y carcinomas indiferenciados de célula grande.Una proporción importante de pacientes expresan de forma simultánea más de una MDR-proteína. Los carcinomas escamosos, son los que con más frecuencia expresan Pgp, Mrp1 y Lrp de forma simultánea. Pgp se expresa fundamentalmente asociada a Lrp.

\section{Palabras clave:}

MDR-proteínas. Cáncer. Pulmón.

\section{Oncología, 2005; 28 (8):378-393}

\footnotetext{
${ }^{1}$ Servicio de Oncología. Hospital Donostia

${ }^{2}$ Departamento de Cirugía. Universidad del País Vasco
} 


\section{Summary}

- Introduction: Lowering of intracellular drug deposition plays an important role in the resistance to chemotherapy of many neoplasms. MDR-proteins regulate the process.

- Material and methods: 147 tumor samples were collected from 143 patients, 35 were obtained by means of bronchoscopy and 112 were surgical specimens; 101 samples from 99 patients were considered correct for final analysis. Samples were cryopreserved and immuno-staining techniques used for MDRproteins characterization (Pgp, Mrp1, and Lrp). A monoclonal murine antibody to each was employed.

- Results: 16 cases failed to express any of the three analysed MDR-proteins. One protein was expressed in 32 cases: 3 Pgp, $11 \mathrm{Mrp1}$, and $18 \mathrm{Lrp}$. The expression of two proteins was observed in 34 cases: 24 Pgp and Lrp, 5 Mrp1 and Pgp, and 5 Mrp1 and Lrp. All the three proteins were expressed in 17 cases. No differences were found in the expression according to age: $\operatorname{Pgp}(\mathrm{p}=0.74), \operatorname{Mrp}(\mathrm{p}=0.95)$ and $\operatorname{Lrp}(\mathrm{p}=0.26)$. Sex showed no differences when considered either number $(\mathrm{p}=0.72)$ or type of proteins $(\mathrm{p}=0.39)$. No significative differences were found according to tumor stage analysing either number $(\mathrm{p}=0.55)$ or type $(\mathrm{p}=0.21)$ of expressed MRDproteins. Differences were also not observed in relation to histologic grade for number $(\mathrm{p}=0.59)$ or type $(\mathrm{p}=0.51)$ of expressed proteins.

A tendency to the simultaneous expression of Pgp and Lrp was very significative $(\mathrm{p}<0.01)$. No similar tendency was observed for the association of Mrp- Lrp ( $\mathrm{p}=0.26)$ and Pgp-Mrp1 ( $\mathrm{p}=0.18)$.

- Conclussions: Lung cancer cells frequently express MDR-proteins. Lrp was the most frequently found in our series. Adenocarcinomas rarely express Mrp1 as compared with other histological classes. Squamous-cell carcinomas express less Lrp than adenocarcinomas and large-cell undifferentiated carcinomas. The simultaneous expression or more than two proteins was observed in a significant number of cases. Squamous-cell carcinomas tend to express Pgp, Mrp1 and Lrp simultaneously. Pgp is ussually expressed associated to Lrp.

Key words: MDR-proteins. Lung. Cancer.

Existen variadas líneas de investigación sobre el cáncer. Muchas de ellas se basan en la búsqueda de nuevos tratamientos. Otras, no menos importantes, intentan averiguar el por qué, a diferencia de bastantes tumores hematológicos como leucemias y linfomas, la mayoría de tumores sólidos, no pueden ser curados con quimioterapia.

Sin duda, las causas de que una célula tumoral sea resistente a la quimioterapia son muchas y de variada naturaleza. El motivo del presente trabajo es el estudio de una de estas posibles causas, en concreto, el de la expresión de proteínas relacionadas con la resistencia a múltiples drogas, en pacientes con cáncer de pulmón.

La resistencia a la quimioterapia, independientemente de los mecanismos que la produzcan, puede ser innata o adquirida. La resistencia innata seria aquella que presenta un tumor sin contacto previo a los fármacos, mientras que la adquirida sería la que aparece tras el contacto con uno o varios de ellos ${ }^{1}$.
Existen dos características tumorales, que parecen determinar la resistencia a la quimioterapia: la cinética de crecimiento ${ }^{2}$, y en estrecha relación con esta, la aparición de mutaciones espontáneas ${ }^{3,4}$.

Muchos tumores al ser tratados con quimioterapia, incluidos los de pulmón, siguen aparentemente las reglas enunciadas por Skipper y Goldie y Cold$\operatorname{man}^{4}$. La mayor parte de los pacientes con cáncer de pulmón no célula pequeña, no responden al tratamiento quimioterápico desde el principio ${ }^{5}$, es decir, presentan resistencia intrínseca o innata.

No existe una definición claramente establecida sobre lo que se considera un tumor "resistente" a nivel clínico. Algunos autores ${ }^{6}$ consideran apropiado emplear criterios de valoración de respuesta a la quimioterapia, como los de la $\mathrm{OMS}^{7}$, considerando sensibles a los tumores con respuesta completa y resistentes o parcialmente resistentes a los demás. Dado que, hasta el momento, no se ha identificado ningún mecanismo que por si solo confiera resistencia a to- 
dos los fármacos conocidos ${ }^{1,8}$, es muy probable, que esta resistencia sea de causa multifactorial.

Clasificar las múltiples causas que pueden originar resistencia a la quimioterapia es difícil ${ }^{1,4,8}$. El objetivo principal del tratamiento quimioterápico es conseguir la muerte de la célula tumoral. Para ello es necesario conseguir que la mayor cantidad de fármaco activo posible, llegue a nivel de su diana molecular, en el interior de la célula. Cualquier circunstancia que se interponga o dificulte este objetivo puede ser causa de resistencia. Tomando como base lo publicado por Lehnert en $1996^{4}$, podríamos clasificar a los factores causantes de resistencia en extracelulares e intracelulares ${ }^{9}$.

La reducción en la acumulación intracelular de los fármacos, es uno de los mecanismos más frecuentes de resistencia a los antineoplásicos. Esto puede producirse por su expulsión a través de la membrana celular ${ }^{10-13}$, por secuestro en vesículas citoplasmáticas ${ }^{6}$, por variaciones en el transporte entre núcleo y citoplasma o por alteración en el metabolismo intracelular del fármaco ${ }^{14}$.

Las alteraciones de la topoisomerasa II son un ejemplo de cómo una variación en la diana molecular de los fármacos, puede ser causante de resistencia a múltiples drogas. La resistencia ligada a estas enzimas ha sido ampliamente estudiada a nivel experimental $^{1,12,15}$.

La célula tumoral puede defenderse de los efectos de la quimioterapia, incluso después de que el medicamento halla alcanzado su objetivo y causado un daño importante ${ }^{4}$. Dos alteraciones celulares destacan a este nivel, un aumento en la capacidad de reparación del $\mathrm{ADN}^{12} \mathrm{y}$, lo que parece más importante, el fallo en la muerte celular programada o apoptosis ${ }^{9}$.

La historia de las proteínas causantes de resistencia a múltiples drogas o MDR-proteínas, se inicia en 1973, con el descubrimiento por Keld Dano ${ }^{16}$, de la expulsión activa de daunomicina en células tumorales resistentes. Pgp es una glucoproteína de membrana con un peso molecular de $170 \mathrm{kD}$, por este motivo se la llama también proteína $\mathrm{P}-170^{17}$. Pgp actúa como una bomba de expulsión ATP-dependiente, reduciendo la acumulación intracelular de varias sustancias. Mrp es en realidad una familia de varios transportadores celulares ${ }^{18}$. Las Mrp se localizan en la membrana plasmática, formando parte, como la Pgp, de los transportadores ABC, pero también en el retículo endoplasmático, de lo que se infiere que puedan actuar tanto en la expulsión de drogas fuera de la célula como en el secuestro intracelular de estas en vesículas citoplasmáticas ${ }^{13}$. Las Mrp son capaces de transportar aniones orgánicos y drogas neutras, conjugadas o no, con sustancias como el glutation, glucoronatos y sulfatos. Se cree que algunos sistemas de expulsión de conjugados de glutation ("GS-X pumps"), pueden ser proteínas de la familia Mrp (19). Tal es el caso de los "GS-X pumas" que expulsan methotrexate (anión orgánico), los cuales se han relacionado con Mrp1, Mrp2, Mrp3 Mrp4, Mrp5, Mrp6 ${ }^{20}$. Por este mismo sistema, también podrían estar relacionadas, con la expulsión de toxinas naturales, sales de metales pesados como el arsénico y con la resistencia a pequeñas moléculas como el cisplatino ${ }^{5,21}$. Lrp es una proteína de 110 kilodaltons descubierta a partir de una línea celular de cáncer de pulmón con MDR no ligada a $\operatorname{Pgp}^{22,23}$. El gen que la codifica se localiza en el cromosoma 16, cercano al de Mrp).Se la conoce también como MVP (Major Vault Protein), porque constituye el componente proteico mayor de unas organelas celulares llamadas vaults ${ }^{24}$. Los vaults, de descripción relativamente reciente ${ }^{25}$, son ribonucleoproteínas con una compleja estructura en forma de barril. Los vaults tienen una composición y estructura casi idénticas en especies filogenéticamente tan alejadas como amebas y humanos, lo que parece indicar que su función es esencial para las células eucariotas.

El cáncer de pulmón por su frecuencia y elevada mortalidad constituye un importante problema sanitario. A pesar de que es posible prevenirlo, incidiendo sobre el hábito de fumar, los datos epidemiológicos actuales no auguran un futuro muy esperanzador, al menos a medio plazo. Su incidencia a nivel mundial aumenta continuamente a expensas de los países industrializados y, sobre todo de los que están camino de ello ${ }^{26}$.

Con los tratamientos actuales solo tienen opción de curación los pacientes diagnosticados en los estadios iniciales de la enfermedad ${ }^{27}$, pero la falta de un método eficaz de diagnóstico precoz, hace que la mayoría de pacientes se presenten con enfermedad avanzada. Además, la incidencia de recidivas tras un tratamiento, en teoría radical, es elevada ${ }^{27}$. Por estos motivos, la mayoría de pacientes con cáncer de pulmón, van a ser candidatos ha recibir tratamiento qui- 
mioterápico en algún momento evolutivo de su enfermedad. Desafortunadamente, los resultados de la quimioterapia son actualmente muy modestos: paliación de síntomas y un discreto aumento de supervivencia.

Los procesos genéticos y bioquímicos que condicionan la aparición de un fenotipo celular resistente a la quimioterapia, han sido objeto de intenso estudio en los últimos años ${ }^{28}$. Esto ha conducido a la identificación de varios mecanismos celulares fundamentales y ha permitido el diseño de estrategias para intentar vencer la resistencia a la quimioterapia. Algunas de estas estrategias han sido o están siendo testadas a nivel clínico.

Los cultivos celulares han sido fundamentales en el desarrollo de los conocimientos en quimiorresistencia. La selección de líneas celulares resistentes a partir de la exposición de los cultivos a los fármacos antineoplásicos, ha permitido identificar mecanismos de resistencia a nivel molecular ${ }^{28}$. Los xenoingertos tumorales en modelos animales y el estudio de muestras neoplásicas de pacientes, han confirmado la presencia de muchos de estos mecanismos en vivo $^{29}$, indicando que similares procesos pueden estar implicados en la resistencia a la quimioterapia en la práctica clínica diaria.

Un prominente mecanismo de resistencia a drogas en las células cancerosas, es la reducción de la concentración intracelular de estas a nivel de su diana celular. Existen al menos dos estrategias celulares capaces de producir esto. El más obvio de estos mecanismos es el que reduce la concentración intracelular de la droga mediante una disminución de su captación y/o un aumento de su excreción. Un segundo mecanismo podría ser el de una redistribución intracelular de la droga, de forma que aunque su concentración intracelular total no varia, la cantidad disponible en su zona de acción es menor. Hasta la actualidad la mayoría de mecanismos asociados a la reducción de la concentración o una redistribución intracelular de la droga se han relacionado con proteínas transportadoras de membrana como Pgp y Mrp1 y con otra de más reciente descubrimiento y mecanismo de acción menos conocido, llamada Lrp. En cultivos celulares la expresión de estas proteínas se relaciona directamente con la resistencia a un gran número de quimioterápicos, por lo que también se las conoce como proteínas relacionadas con la resistencia a múltiples drogas o
MDR-proteínas.

No existen en la actualidad datos concluyentes sobre si la expresión de estas proteínas puede estar implicada en la resistencia a la quimioterapia del cáncer de pulmón. La resistencia a la quimioterapia de los enfermos con cáncer de pulmón es un hecho evidente en la práctica clínica diaria. De forma intrínseca o adquirida esta resistencia afecta a variados agentes antineoplásicos, por lo que presumiblemente se deba a múltiples factores.

\section{Objetivos}

Los objetivos del presente trabajo son los siguientes:

1. Determinar mediante estudio inmunohistoquímico, la expresión de las proteínas Pgp, Mrp1 y Lrp (MDR-proteínas), en muestras tumorales de pacientes afectos de cáncer de pulmón.

2. Determinar la relación entre la expresión individual de cada MDR-proteínas en relación al tipo histológico, diferenciación tumoral y estadio tumoral.

\section{Material y métodos}

El presente estudio se ha realizado en muestras de tejido tumoral de pacientes diagnosticados y/o tratados de cáncer de pulmón en el Hospital Donostia de San Sebastián entre Abril de 1995 y Junio de 1997.

\section{Obtención y conservación de muestras}

1. Muestras quirúrgicas: Durante el acto quirúrgico, se tomaban dos muestras de la zona tumoral que se introducían en criotubos y se almacenaban en una cubeta portátil de nitrógeno líquido hasta su procesamiento.

2. Muestras broncoscópicas: Se tomaba una muestra que era tratada del mismo modo que las piezas quirúrgicas.

Se recogieron 147 muestras tumorales procedentes de 143 pacientes. De éstas, 35 eran broncoscópicas y 112 quirúrgicas. De 4 pacientes se dispuso de muestra quirúrgica y broncoscópica. No fueron validas para el estudio 46 muestras: 27 broncoscópicas 


\section{TABLA I}

Distribución de los 99 pacientes con respecto a las variables clinico-patológicas

\begin{tabular}{|c|c|}
\hline Edad & Media 64 años (36-83) \\
\hline Sexo & $\begin{array}{l}85 \text { Hombres } \\
14 \text { Mujeres }\end{array}$ \\
\hline Estadio & 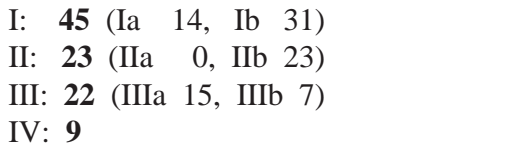 \\
\hline Histología & 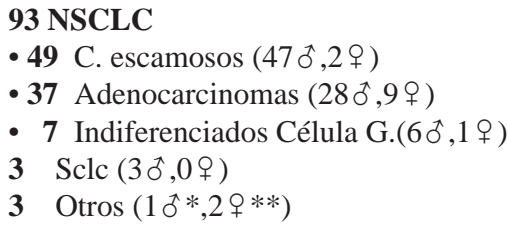 \\
\hline $\begin{array}{l}\text { Grado } \\
\text { histológico }\end{array}$ & $\begin{array}{l}20 \text { Bien Dif } \\
35 \text { Mod Dif } \\
43 \text { Pob Dif } \\
1 \text { Desconocido }\end{array}$ \\
\hline
\end{tabular}

* Carc. con diferenciación neuroendocrina, t. carcinoide.

** Carc. sin especificar.

TABLA II

Procedencia y validez para el estudio de las 147 muestras recogidas

\begin{tabular}{|ccccc|}
\hline & Procedencia & Totales & Válidas & No válidas \\
\hline \multirow{4}{*}{ Total } & Quirófano & 112 & 93 & 19 \\
& Broncoscopia & 35 & 8 & 27 \\
& & $\mathbf{1 4 7}$ & $\mathbf{1 0 1 *}$ & $\mathbf{4 6}$ \\
\hline
\end{tabular}

* Las 101 muestras válidas pertenecían a 99 ptes. (2 ptes tenían muestra quirúrgica y broncoscópica).

por ausencia de tumor y 19 quirúrgicas, de las cuales 15 lo fueron por ausencia de tumor, 3 por tratamiento quimioterápico previo, y 1 por tumor de origen no pulmonar. Resultaron válidas para el estudio 101 muestras correspondientes a 99 pacientes. En dos pacientes se dispuso de muestra broncoscópica y quirúrgica, optándose por procesar únicamente la quirúrgica. Finalmente, el estudio se realizó en 99 muestras de 99 pacientes, 6 de ellas broncoscópicas y 93 quirúrgicas (Tablas I y II).

\section{Estudio inmunohistoquímico de las muestras tumorales}

Las muestras tumorales criocongeladas fueron sometidas a análisis inmunohistoquímico para la detección de las tres MDR-proteínas, Pgp, Mrp1 y Lrp. Para ello se utilizó la técnica comercial de estreptavidina-biotina (LSAB de DAKO), junto con anticuerpos monoclonales no comerciales, procedentes de un laboratorio de investigación universitario - Universidad Libre de Ámsterdam -.

\section{Reactivos utilizados:}

Anticuerpos monoclonales:

MRPr1 reconoce la proteína Mrp1

MRPm6 reconoce la proteína Mrp1

LRP-56 reconoce la proteína Lrp

JSB-1 reconoce la proteína Pgp

Sistema de visualización LSAB y Kits de diamonobenzidina (Dako)

\section{Acetona}

Suero bovino

PBS (bufer fosfato salino)

\section{Descripción de los anticuerpos monoclonales (AcMo):}

AcMo MRPr1: IgG isotipo 2a de rata, obtenido a partir de una proteína de fusión bacteriana de Mrp1 que contenía un segmento de 168 aminoácidos en la mitad amino-proximal de la proteína. Se produce a partir de células híbridas resultantes de la fusión entre células linfáticas de rata inmunizada y células SP2/O de mieloma de ratón.

$M R P r 1$ reacciona con epitopo de Mrp1. No presenta reacción cruzada con los productos de los genes humanos MDR1 y MDR3.

AcMo MRPm6: IgG isotipo 1 de ratón, obtenido a partir de una proteína de fusión bacteriana de Mrp1 que contenía un segmento de 170 aminoácidos en el extremo carboxiterminal y parte del dominio de unión carboxiproximal de la proteína. MRPm6 reacciona con un epitopo interno de Mrp1. Se produce a partir de células híbridas resultantes de la fusión entre células linfáticas de ratón inmunizado y células SP2/O de mieloma de ratón. No presenta reacción cruzada con los productos de los genes humanos MDR1 y MDR3.

AcMo LRP-56: IgG isotipo 2b. Reacciona con un epitopo interno de Lrp. Se produce a partir de célu- 
las híbridas resultantes de la fusión entre células linfáticas de ratón inmunizado y células SP2/O de mieloma de ratón.

AcMo JSB 1: IgG isotipo 1. Reacciona con un epitopo citoplasmático de Pgp. Se produce a partir de células híbridas resultantes de la fusión entre células linfáticas de ratón inmunizado y células SP2/O de mieloma de ratón.

\section{Descripción de la técnica:}

$1^{\circ}$ De cada muestra tumoral crioalmacenada se realizan en el criostato 5 cortes de 4 micras (C-1, C-2, C-3, C-4 y control negativo) que se dejan secar a temperatura ambiente

$2^{\circ} 15^{\prime}$ en acetona y dejar secar

$3^{\circ}$ Incubación en suero bovino durante 15,

$4^{\circ}$ Incubación directa con el Anticuerpo Monoclonal correspondiente durante 1 hora, diluido en suero bovino y PBS a partes iguales, con cada uno de los cortes, a excepción del corte control negativo.

$5^{\circ}$ lavado en PBS

$6^{\circ}$ Avidina 30'

$7^{\circ}$ Lavado en PBS

$8^{\circ}$ Streptavidina 30'

$9^{\circ}$ lavado en PBS

$10^{\circ}$ incubación DAB 7'

$11^{\circ}$ lavado PBS

$12^{\circ}$ Contrastar con hematoxilina de Harrys $1^{\prime}$

$13^{\circ}$ Lavado en agua

$14^{\circ}$ Virar en agua amoniacal

$15^{\circ}$ Deshidratar y montar

Todas las incubaciones se realizaron en cámara húmeda y a temperatura ambiente.

Se empleó tejido normal de colón como control positivo, el cual presenta alta expresión de estas proteínas. El $5^{\circ}$ corte histológico, de cada muestra tumoral, se utilizó como control negativo, sometido a todo el proceso técnico a excepción de la incubación con el anticuerpo primario ( $4^{\circ}$ paso). Como control negativo se utilizó un antisuero inespecífico tipo $\mathrm{IgG}$, de ratón.

\section{Variables del estudio}

Variable dependiente: expresión de Mdr-proteínas

Se cuantificó la proporción de células que reac-
TABLA III

Expresión de MDR-proteínas en los 99 pacientes de la serie

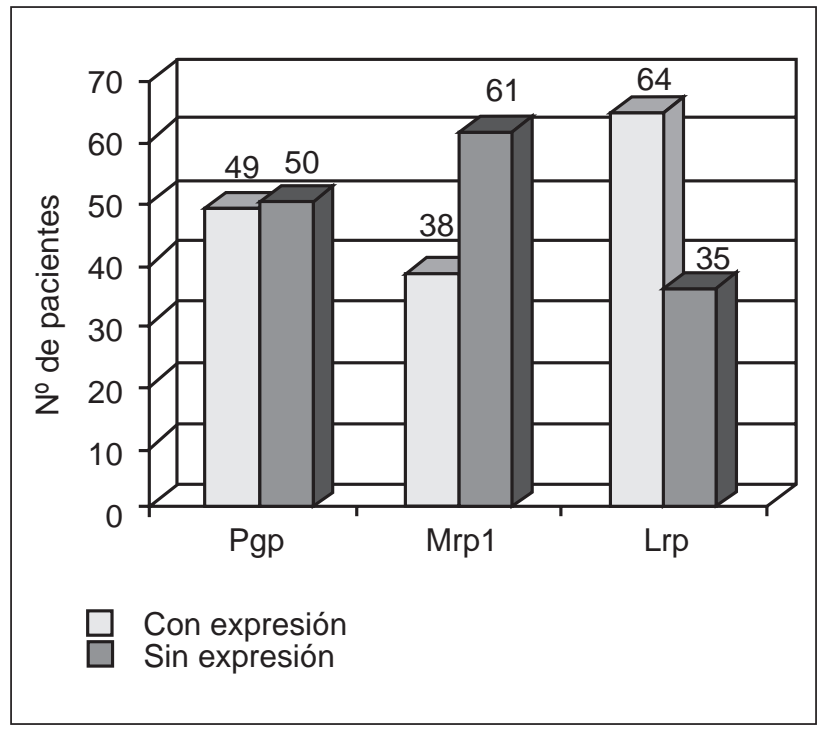

cionaban con el AcMo (Tabla III). Se consideró como positiva, cuando un $10 \%$ o más de las células de la preparación expresaban la proteína. El estudio de la expresión de MDR-proteínas y su relación con las diferentes variables clinico-patológicas se realizó de dos formas:

1. Individual o independiente: Analizamos la expresión de cada proteína por separado, sin tener en cuenta si se expresaba sóla o asociada a las otras.

2. Simultáneo: Analizamos la expresión conjunta de MDR-proteínas en los pacientes desde diferentes puntos de vista:

- Expresión positiva fente a expresión negativa: Con independencia del número o tipo de proteína expresada.

- Número de proteínas expresadas simultáneamente con independencia del tipo: Ninguna, una, dos, o tres.

- Número y Tipo de MDR-proteínas expresadas simultaneamente: Ninguna, Pgp, Mrp1, Lrp, Pgp+Lrp, Mrp1+Pgp, Mrp1+Lrp, y las tres a la vez.

Variables independientes

\section{Edad:}

1. Sexo. 
2. Tipo histológico: Las muestras fueron clasificadas, mediante examen en microscopio óptico tras tinción con hematoxilina y eosina ( $\mathrm{H} \&$ E), siguiendo los criterios de la $\mathrm{OMS}^{30}$ en los siguintes tipos histológicos: Carcinomas escamosos, adenocarcinomas, carcinomas indiferenciados de célula grande, carcinomas indiferenciados de célula pequeña y otros.

3. Grado de diferenciación histológico: Se determinó el grado histológico de las muestras por tinción con $\mathrm{H} \& \mathrm{E}$ y examen al microscopio óptico. Fue la zona más indiferenciada de la muestra la que marco el grado, quedando este clasificado en uno de los siguientes grupos: bien diferenciado, moderadamente diferenciado, pobremente diferenciado

4. Estadio tumoral: Se estableció por el sistema TNM, según la clasificación de la UICC $1997^{31}$. Se utilizó el estadio clínico en aquellos casos no tratados quirúrgicamente y el estadio patológico en los que si lo fueron.

\section{Variables clinico-patológicas (variables} independientes)

\section{Examen Anatomopatológico}

A partir del estudio histoquímico de las muestras criocongeladas, mediante examen en microscopio óptico tras tinción con hematoxilina y eosina $(\mathrm{H} \&$ E), se comprobó la presencia de tumor y se determinaron las siguientes variables: Tipo histológico y Grado de diferenciación histológico.

\section{Revisión de historiales clínicos}

De los historiales clínicos de los pacientes se recogieron los datos correspondientes a las siguientes variables: edad, sexo, estadio tumoral, intervalo libre de enfermedad, supervivencia y respuesta al tratamiento quimioterápico. Para concretar los tres últimos se realizaron revisiones periódicas, la última en Marzo del 2004. Para determinar la supervivencia fue necesario el contacto telefónico en varios casos, y en otros se consulto el registro de mortalidad del País Vasco, si bien no incluidos en el presente trabajo.

\section{Resultados}

\section{Variables clínico-patológicas}

La edad media de los 99 pacientes fue de $64+/-$ 10,2 años. La serie se compone de 85 hombres y 14 mujeres con una media de edad de $64+/-9,7$ años para los hombres y de 61+/- 13 años para las mujeres. Presentaban tumores con histología no célula pequeña, 93 pacientes (49 carcinomas escamosos,

TABLA IV

$\mathrm{N}^{\circ}$ y Tipo de Mdr-proteínas expresadas simultáneamente

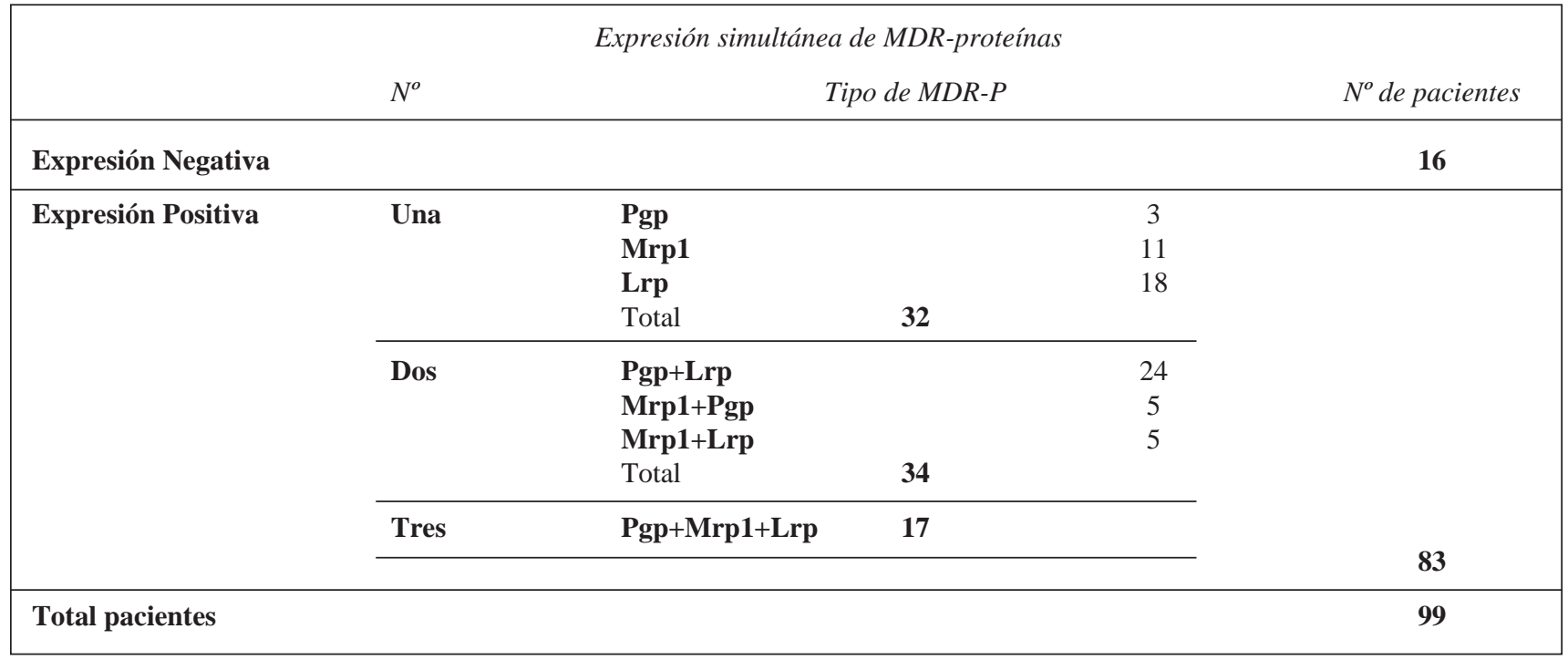

$\mathrm{P}<0,01$ 
37 adenocarcinomas y 7 carcinomas indiferenciados de célula grande), 3 carcinomas indiferenciados de célula pequeña y 3 con otras histologías ( 1 carcinoma con diferenciación neuroendocrina, 1 carcinoma sin más especificación y 1 tumor carcinoide). Con respecto al grado de diferenciación histológica, en 20 casos fue bien diferenciado, en 35 moderadamente diferenciado, en 43 pobremente diferenciado, y en 1 paciente no pudo especificarse el grado. Por estadios los 99 pacientes se agruparon de la siguiente forma: Estadio I, 45 casos (Ia 14, Ib 31). Estadio II, 23 casos (IIA 0, IIB 23). Estadio III, 22 casos (IIIA 15, IIIB 7). Estadio IV, 9 casos.

\section{Expresión de MDR-proteínas}

En el análisis de la expresión independiente de cada Mdr-proteína, los resultados fueron los siguientes:

- Pgp: Sin expresión 50 (50,5\%) pacientes, con expresión 49 (49,5\%).

- Mrp1: Sin expresión 61 (61,6\%) pacientes, con expresión 38 (38,4\%).

- Lrp: Sin expresión 35 (35,4\%) pacientes, con expresión $64(64,6 \%)$.

Con respecto a Mrp1, 30 de los 38 pacientes que la expresaban presentaron positividad para los dos anticuerpos monoclonales empleados, mientras que 8 (4 para cada AcMo) fueron positivos solo a uno de ellos. 83 de los 99 pacientes expresaban alguna MDR-proteína, y 16 no expresaban ninguna. La distribución fue la siguiente (Tabla IV):

- Sin expresión de proteínas: No expresaban ninguna proteína, 16 casos.

- Expresión de una proteína: Expresaban una sola proteína, 32 casos: 3 Pgp, 11 Mrp1 y 18 Lrp $=0$.

- Expresión de dos proteínas: Expresaban dos proteínas, 34 casos: 24 Pgp y Lrp, 5 Mrp1 y Pgp, 5 Mrp1 y Lrp=0.

- Expresión de las tres proteínas: Expresaban las tres proteínas, 17 casos

\section{Expresión de MDR-proteínas y su relación con las variables clínico-patológicas}

\section{Edad}

En el análisis de la expresión independiente de

\section{TABLA V}

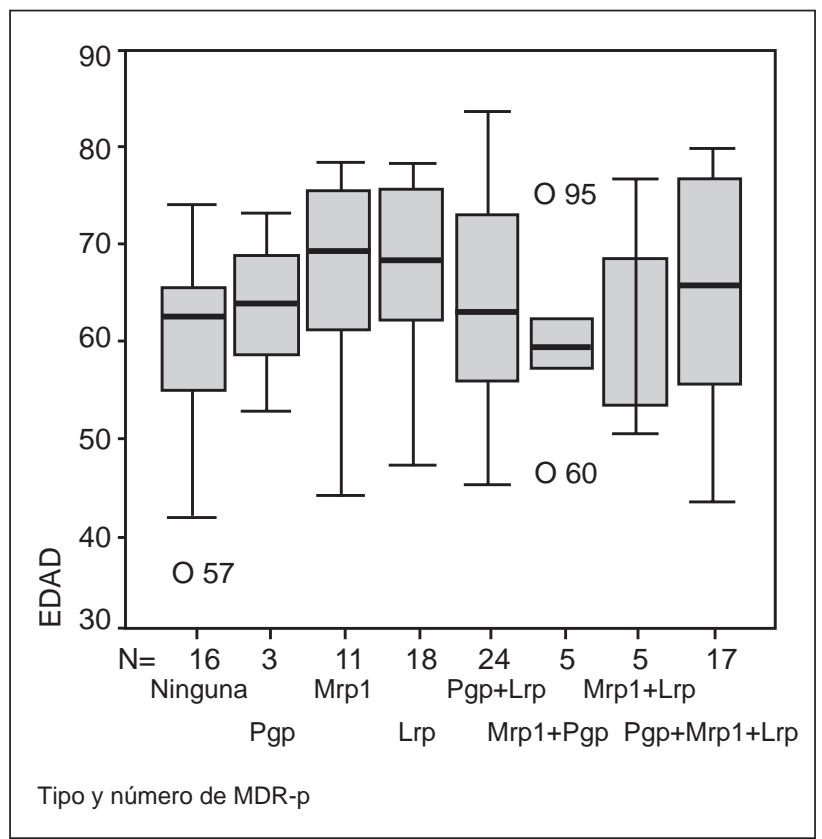

cada Mdr-proteína, con respecto a la edad, los resultados fueron los siguientes (Tabla V):

- Pgp: La media de edad de los pacientes con expresión de Pgp fue de 63,7+/- 10,5años (rango: 43-83) y la de los pacientes sin expresión de 64,4 78+/- 10 (rango: 36-78+/- 10).

- Mrp1: La media de edad de los pacientes con expresión de Mrp1 fue de 64+/-10,6 años (rango 43-79) y la de los pacientes sin expresión de 64,1+/-10 (rango: 36-83).

- Lrp: La media de edad de los pacientes con expresión de Lrp fue de 64,9+/-10,2 años (rango:43-83) y la de los pacientes sin expresión de 62,5+/-10,2 (rango:36-78).

No hemos detectado relación significativa entre la edad y la expresión de Pgp $(\mathrm{p}=0.74)$, Mrp1 $(\mathrm{p}=0.95)$, o $\operatorname{Lrp}(\mathrm{p}=0.26)$.

\section{Sexo}

En el análisis de la expresión independiente de cada Mdr-proteína, con respecto al sexo, los resultados fueron los siguientes (Tabla VI):

- Pgp: De las 14 mujeres, 5 expresaban Pgp (35,7\%), y de los 85 hombres, 44 (51,8\%).

- Mrp1: De las 14 mujeres, 2 expresaban Mrp1 $(14,3 \%)$, y de los 85 hombres, 36 (42,4\%). 
TABLA VI

\% de Expresión de cada MDR-proteína en relación al sexo

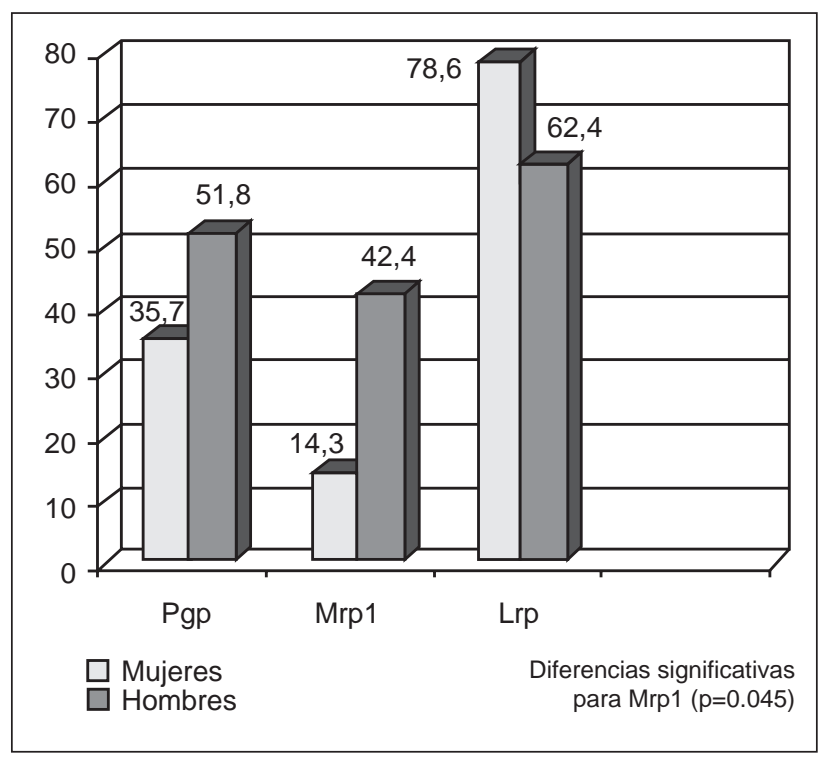

- Lrp: De las 14 mujeres, 11 expresaban Lrp (78,6\%), y de los 85 hombres, $53(62,4 \%)$.

Hemos encontrado diferencias significativas entre los dos sexos, en la expresión individual de $\operatorname{Mrp} 1(\mathrm{p}=0,045)$, pero no de $\operatorname{Pgp}(\mathrm{p}=0.26)$, o Lrp $(\mathrm{p}=0.24$

Al estudiar la expresión simultánea de MDR-proteínas, los resultados fueron los siguientes:

- Sin expresión de proteínas: De las 14 mujeres, $3(21,4 \%)$ no expresaban ninguna proteína. De los 85 hombres, 13 (15,3\%).

- Expresión de una proteína: De las 14 mujeres, $5(35,7 \%)$ expresaban solo una proteína: 5 Lrp=0. De los 85 hombres, 27 (31,8\%): 3 Pgp, 11 Mrp1, 13 Lrp=0.

- Expresión de dos proteínas: De las 14 mujeres, $5(35,7 \%)$ expresaban dos proteínas: 4 Pgp y Lrp, 1 Mrp1 y Lrp=0. De los 85 hombres, 29 (34,1\%): 20 Pgp y Lrp, 5 Mrp1 y Pgp, 4 Mrp1 y Lrp=0.

- Expresión de las tres proteínas: De las 14 mujeres, $1(7,1 \%)$ expresaban las tres proteínas. De los 85 hombres, $16(18,8 \%)$.

No detectamos diferencias significativas entre sexos, tanto al analizar por el número $(\mathrm{p}=0.72)$, como por el tipo $(\mathrm{p}=0.39)$ de proteínas expresadas de forma simultánea.

\section{Histología}

En el análisis de la expresión independiente de cada Mdr-proteína, con respecto a la histología, los resultados fueron los siguientes:

- Pgp: De los 49 carcinomas escamosos, expresaban Pgp 26 (53,1\%), de los 37 adenocarcinomas lo hacían $20(54,1 \%)$, de los 7 carcinomas indiferenciados de célula grande $3(42,9 \%)$, de los 3 carcinomas indiferenciados de célula pequeña ninguno $(0 \%)$ y de los 3 casos con otras histologías ninguno $(0 \%)$.

- Mrp1: De los 49 carcinomas escamosos, expresaban Mrp1 31 (63,3\%), de los 37 adenocarcinomas lo hacían $2(5,4 \%)$, de los 7 carcinomas indiferenciados de célula grande 3 (42,9\%), de los 3 carcinomas indiferenciados de célula pequeña $1(33,3 \%)$ y de los 3 casos con otras histologías 1 , el caso definido como carcinoma sin más especificación $(33,3 \%)$.

- Lrp: De los 49 carcinomas escamosos, expresaban Lrp 29 (59,2\%), de los 37 adenocarcinomas lo hacían $29(78,4 \%)$, de los 7 carcinomas indiferenciados de célula grande $6(85,7 \%)$, de los 3 carcinomas indiferenciados de célula pequeña ninguno $(0 \%)$ y de los 3 casos con otras histologías ninguno $(0 \%)$.

Hemos encontrado diferencias significativas entre los diferentes tipos histológicos con respecto a la expresión individual de Mrp1 $(\mathrm{p}=0.01)$, o Lrp $(\mathrm{p}=0.01)$, pero no de $\operatorname{Pgp}(\mathrm{p}=0.16)$ (Tabla VII).

Al estudiar la expresión simultánea de MDR-proteínas, Encontramos que expresaban alguna proteína el $100 \%$ (7/7) de los carcinomas indiferenciados de célula grande, el 90\% (44/49) de carcinomas escamosos, el $81 \%$ (31/37) de adenocarcinomas, 1 de los 3 carcinomas indiferenciados de célula pequeña y el caso del carcinoma sin más especificación, siendo la distribución la siguiente:

- Sin expresión de proteínas: De los 49 carcinomas escamosos no expresaban ninguna proteína $5(10,2 \%)$, de $\operatorname{los} 37$ adenocarcinomas 7 $(18,9 \%)$, de los 7 carcinomas indiferenciados de célula grande ninguno $(0 \%)$, de los 3 carcinomas indiferenciados de célula pequeña 2 $(66,6 \%)$ y de los 3 casos con otras histologías 2 , el carcinoma con diferenciación neuroendocrina $\mathrm{y}$ el tumor carcinoide $(66,6 \%)$. 
TABLA VII

$\mathbf{N}^{\circ}$ de Mdr-proteínas expresadas simultaneamente, en relación a la histología

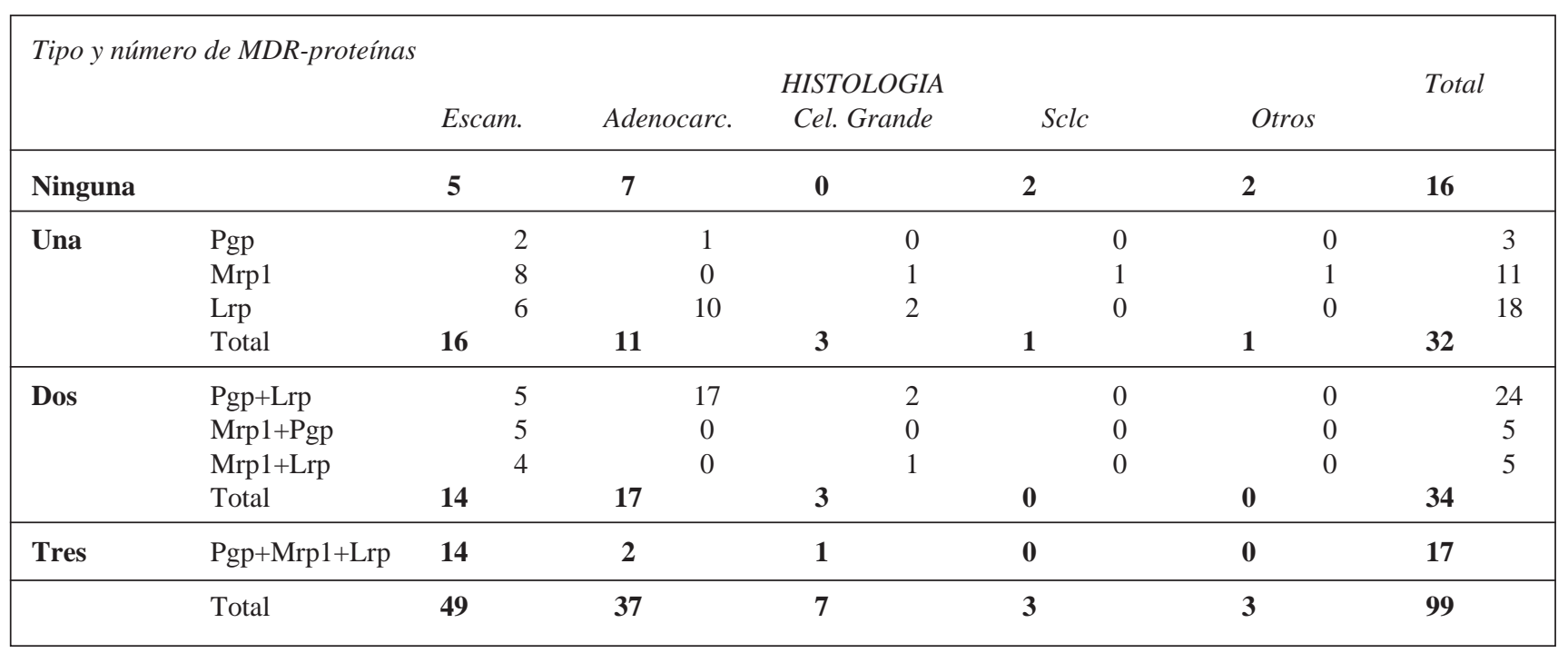

$\mathrm{p}=0.002$

- Expresión de una sola proteína: De los 49 carcinomas escamosos expresaban una sola proteína 16 (32,7\%): 2 Pgp, 8 Mrp1, 6 Lrp=0. De los 37 adenocarcinomas 11 (29,7\%): 1 Pgp, 10 Lrp=0. De los 7 carcinomas indiferenciados de célula grande $3(42,9 \%): 1$ Mrp1, 2 Lrp=0. De los 3 carcinomas indiferenciados de célula pequeña 1 (33,3\%): Mrp1. De los 3 casos con otras histologías 1, el caso definido como carcinoma sin más especificación (33,3\%): Mrp1.

- Expresión de dos proteínas: De los 49 carcinomas escamosos expresaban dos proteínas 14 (28,6\%): 5 Pgp y Lrp, 5 Mrp1 y Pgp, 4 Mrp1 y $\mathrm{Lrp}=0$. De los 37 adenocarcinomas 17 (45,9\%): 17 Pgp y Lrp $=0$. De los 7 carcinomas indiferenciados de célula grande 3 (42,9\%): 2 Pgp y Lrp, 1 Mrp1 y Lrp=0. De los 3 carcinomas indiferenciados de célula pequeña ninguno $(0 \%)$. De los 3 casos con otras histologías ninguno (0\%).

- Expresión de las tres proteínas: De los 49 carcinomas escamosos expresaban las tres proteínas $14(28,6 \%)$. De los 37 adenocarcinomas 2 (5,4\%). De los 7 carcinomas indiferenciados de célula grande 1 (14,3\%). De los 3 carcinomas indiferenciados de célula pequeña ninguno $(0 \%)$. De los 3 casos con otras histologías ninguno $(0 \%)$.
Al realizar el análisis de la expresión simultánea de MDR-proteínas, también detectamos diferencias significativas entre los diferentes tipos histológicos, tanto para el número $(\mathrm{p}=0.02)$, como para el tipo $(\mathrm{p}=0.002)$ de MDR-proteínas expresadas simultáneamente.

\section{Grado de diferenciación}

En el análisis de la expresión independiente de cada Mdr-proteína, con respecto al grado de diferenciación, los resultados fueron los siguientes:

- Pgp: De de los 20 tumores bien diferenciados expresaban Pgp 13 (65\%), de los 35 moderadamente diferenciados $16(45,7 \%)$, y de los 43 pobremente diferenciados $20(46,5 \%)$.

- Mrp1: De de los 20 tumores bien diferenciados expresaban Mrp1 10 (50\%), de los 35 moderadamente diferenciados $11(31,4 \%)$, y de los 43 pobremente diferenciados $16(37,2 \%)$.

- Lrp: De de los 20 tumores bien diferenciados expresaban Lrp 14 (70\%), de los 35 moderadamente diferenciados $25(71,4 \%)$, y de los 43 pobremente diferenciados $25(58,1 \%)$.

No hemos encontrado diferencias significativas entre los diferentes grados histológicos con respecto a la expresión individual de Pgp ( $\mathrm{p}=0.35)$, Mrp1 $(\mathrm{p}=0.32)$, o $\operatorname{Lrp}(\mathrm{p}=0.31)$. 
TABLA VIII

$\mathbf{N}^{0}$ de Mdr-proteínas expresadas; , en relación con el Estadio Tumoral. Tabla de contingencia

\begin{tabular}{|c|c|c|c|c|c|c|}
\hline & & & ESTADIC & MORAL & & Total \\
\hline & & Estadio I & Estadio II & Estadio III & Estadio IV & \\
\hline Tipo y número de MDR-p & Ninguna & 10 & 2 & 2 & 2 & 16 \\
\hline & & $22,2 \%$ & $8,7 \%$ & $9,1 \%$ & $22,2 \%$ & $16,2 \%$ \\
\hline & Pgp & 1 & 2 & 0 & 0 & 3 \\
\hline & & $2,2 \%$ & $8,7 \%$ &, $0 \%$ &, $0 \%$ & $3,0 \%$ \\
\hline & Mrp1 & 5 & 1 & 2 & 3 & 11 \\
\hline & & $11,1 \%$ & $4,3 \%$ & $9,1 \%$ & $33,3 \%$ & $11,1 \%$ \\
\hline & Lrp & 5 & 8 & 4 & 1 & 18 \\
\hline & & $11,1 \%$ & $34,8 \%$ & $18,2 \%$ & $11,1 \%$ & $18,2 \%$ \\
\hline & Pgp+Lrp & 12 & 3 & 7 & 2 & 24 \\
\hline & & $26,7 \%$ & $13,0 \%$ & $31,8 \%$ & $22,2 \%$ & $24,2 \%$ \\
\hline & Mrp1+Pgp & 3 & 1 & 1 & 0 & 5 \\
\hline & & $6,7 \%$ & $4,3 \%$ & $4,5 \%$ &, $0 \%$ & $5,1 \%$ \\
\hline & Mrp1+Lrp & 0 & 3 & 2 & 0 & 5 \\
\hline & &, $0 \%$ & $13,0 \%$ & $9,1 \%$ &, $0 \%$ & $5,1 \%$ \\
\hline & Pgp+Mrp1+Lrp & 9 & 3 & 4 & 1 & 17 \\
\hline & & $20,0 \%$ & $13,0 \%$ & $18,2 \%$ & $11,1 \%$ & $17,2 \%$ \\
\hline Total & & 45 & 23 & 22 & 9 & 99 \\
\hline & & $100,0 \%$ & $100,0 \%$ & $100,0 \%$ & $100,0 \%$ & $100,0 \%$ \\
\hline
\end{tabular}

$\mathrm{p}=0.21$

En el análisis de la expresión simultánea de MDR-proteínas, encontramos que expresaban alguna de estas el 90\% (18/20) de los tumores bien diferenciados, el $82,9 \%(29 / 35)$ de los moderadamente diferenciados, y el 81,4\% (35/43) de los pobremente diferenciados, siendo la distribución la siguiente:

- Sin expresión de proteínas: De los 20 tumores bien diferenciados no expresaban ninguna proteína $2(10 \%)$, de los 35 moderadamente diferenciados $6(17,1 \%)$, y de los 43 pobremente diferenciados $8(18,6 \%)$.

- Expresión de una sola proteína: De los 20 tumores bien diferenciados expresaban una sola proteína 5 (25\%), de los 35 moderadamente diferenciados $10(28,6 \%)$, y de los 43 pobremente diferenciados $16(37,2 \%)$.

- Expresión de dos proteínas: De los 20 tumores bien diferenciados expresaban dos proteínas 7 (35\%): 5 Pgp y Lrp, 2 Mrp1 y Pgp=0. De los 35 moderadamente diferenciados 15 (42,9\%): 11 Pgp y Lrp, 1 Mrp1 y Pgp, 3 Mrp1 y Lrp=0. De los 43 pobremente diferenciados 12 (27,9\%): 8 Pgp y Lrp, 2 Mrp1 y Pgp, 2 Mrp1 y Lrp $=0$.
- Expresión de las tres proteínas: De los 20 tumores bien diferenciados expresaban las tres proteínas $6(30 \%)$, de los 35 moderadamente diferenciados $4(11,4 \%)$, y de los 43 pobremente diferenciados $7(16,3 \%)$.

Tampoco detectamos diferencias significativas entre los diferentes grados histológicos, tanto para el número $(\mathrm{p}=0.59)$, como para el tipo $(\mathrm{p}=0.51)$ de MDR-proteínas expresadas simultáneamente.

\section{Estadio}

En el análisis de la expresión independiente de cada Mdr-proteína, con respecto al estadio, los resultados fueron los siguientes (Tabla VIII):

- Pgp: De los 45 estadios I expresaban Pgp 25 $(55,6 \%)$, de los 23 estadios II $9(39,1 \%)$, de los 22 estadios III 12 (54,5\%), y de los 9 estadios IV $3(33,3 \%)$.

- Mrp1: De los 45 estadios I expresaban Mrp1 17 (37,8\%), de los 23 estadios II 8 (34,8\%), de los 22 estadios III 9 (40,9\%), y de los 9 estadios IV $4(44,4 \%)$. 
- Lrp: De los 45 estadios I expresaban Lrp 26 (57,8\%), de los 23 estadios II 17 (73,9\%), de los 22 estadios III 17 (77,3\%), y de los 9 estadios IV $4(44,4 \%)$.

No hemos encontrado diferencias significativas entre los diferentes estadios con respecto a la expresión individual de Pgp ( $\mathrm{p}=0.42)$, Mrp1 ( $\mathrm{p}=0.95)$, o $\operatorname{Lrp}(\mathrm{p}=0.17)$.

Al realizar el análisis de la expresión simultánea de MDR-proteínas, encontramos que expresaban alguna de estas el 77,8\% (35/45) de los tumores en estadio I, el 91,3\% (21/23) de los estadios II, el 90,9\% (20/22) de los estadios III, y el 77,8\% (7/9) de los tumores en estadio IV, siendo la distribución la siguiente:

- Sin expresión de proteínas: De los 45 tumores en estadio I no expresaban ninguna proteína 10 $(22,2 \%)$, de los 23 en estadio II $2(8,7 \%)$, de los 22 en estadio III $2(9,1 \%)$, y de los 9 en estadio IV $2(22,2 \%)$.

- Expresión de una sola proteína: De de los 45 tumores en estadio I expresaban una sola proteína $11(24,4 \%)$ : 1 Pgp, 5 Mrp1 y 5 Lrp=0. De los 23 en estadio II 11 (47,8\%): 2 Pgp, 1 Mrp1 y 8 $\mathrm{Lrp}=0$. De los 22 en estadio III 6 (27,3\%): 2 Mrp 1 y 4 Lrp=0. De los 9 en estadio IV 4 (44,4\%): 3 Mrp1 y 1 Lrp=0.

- Expresión de dos proteínas: De de los 45 tumores en estadio I expresaban dos proteínas 15 (33,3\%): 12 Pgp y Lrp, 3 Mrp1 y Pgp=0. De los 23 en estadio II 7 (30,4\%): 3 Pgp y Lrp, 1 Mrp1 y Pgp, y 3 Mrp1 y Lrp=0. De los 22 en estadio III 10 (45,5\%): 7 Pgp y Lrp, 1 Mrp1 y Pgp, y 2 Mrp1 y Lrp=0. De los 9 en estadio IV 2 (22,2\%): 2 Pgp y Lrp=0.

- Expresión de las tres proteínas: De de los 45 tumores en estadio I expresaban las tres proteínas 9 (20\%), de los 23 en estadio II 3 (13,0\%), de los 22 en estadio III 4 (18,2\%), y de los 9 en estadio IV $1(11,1 \%)$.

Tampoco detectamos diferencias significativas entre los diferentes estadios tumorales, tanto para el número $(\mathrm{p}=0.55)$, como para el tipo $(\mathrm{p}=0.21)$ de MDR-proteínas expresadas simultáneamente.

\section{Analisis de la asociacion entre MDR-proteínas}

Hemos estudiado la tendencia de las MDR-proteí- nas a expresarse en solitario o asociadas a las otras, con los siguientes resultados:

- Pgp: De los 49 casos en que se expresó esta proteina, en 3 (6\%) lo hizo sola, y en 46 (93\%) asociada: con Lrp en 24, con Mrp1 en 5 y en 17 con Lrp y Mrp1 a la vez.

- Mrp1: De los 38 casos en que se expresó esta proteina, en 11 (29\%) lo hizo sola, y en 27 (71\%) asociada: con Pgp en 5, con Lrp en 5 y en 17 con Pgp y Lrp a la vez.

- Lrp: De los 64 casos en que se expresó esta proteina, en 18 (28\%) lo hace sola, y en 46 (72\%) asociada: con Pgp en 24, con Mrp1 en 5 y en 17 con Pgp y Mrp1 a la vez.

La tendencia de Pgp y Lrp a expresase asociadas ha resultado muy significativa $(\mathrm{p}=0.000)$, no ocurrió lo mismo para la sociación Pgp y Mrp1 ( $\mathrm{p}=0.18)$ o Mrp1 y Lrp (p=0.26).

\section{Discusión}

El primer paso para averiguar si los mecanismos causantes de resistencia a múltiples drogas in vitro, están implicados en los malos resultados de la quimioterapia en el cáncer de pulmón, seria demostrar la presencia de alguno o varios de estos mecanismos en los pacientes con dicho tumor. Dada la frecuencia de esta neoplasia, cualquier mejora en la eficacia del tratamiento por pequeña que fuese, podría beneficiar a miles de personas. La resistencia a la quimioterapia es uno de los principales obstáculos a superar para mejorar esta eficacia.

Nuestro estudio tenía como primer objetivo determinar la expresión de tres MDR-proteínas en el cáncer de pulmón. Los resultados de nuestro estudio confirman la presencia de MDR-proteínas en el cáncer de pulmón. La proteína más expresada fue Lrp, con positividad en el $64 \%$ de pacientes, seguida de Pgp en $49 \%$ y Mrp1 en 38\%. Estos resultados son parecidos a los que refleja la literatura. Los trabajos iniciales sobre MDR-proteínas en cáncer de pulmón estudiaban la expresión de Pgp y se realizaron hace ya algunos años. Estos primero estudios, salvo el publicado por Radosevich en $1989^{32}$, detectaron una baja expresión de esta proteína, por lo que durante algunos años se acepto como establecido que Pgp no se expresaba en el cáncer de pulmón y por lo tanto 
no podía influir en el mal resultado de la quimioterapia. Posteriores estudios han demostrado una mayor expresión de Pgp, que por inmunohistoquímica se situa entre un $35 \%$ y un $52 \%$. Sobre muestras congeladas, Beer y cols ${ }^{27}$ y Scagliotti y cols ${ }^{33}$, encontraron una expresión del 35\% y $41 \%$ respectivamente en pacientes con carcinomas de pulmón no célula pequeña. Nosotros hemos encontrado un $49 \%$ de expresión de Pgp, 51\% si consideramos solo los casos de carcinoma no célula pequeña, resultado parecido a lo publicado por estos autores y que confirma la existencia de una expresión relevante de Pgp en estos tumores.

El abanico de resultados publicados para Mrp1 es más amplio, y se sitúa entre el $38 \%$ y el $88 \%$, pero ninguno de los trabajos con un número considerable de casos empleamaterial congelado. El resultado de nuestro estudio se sitúa en un nivel bajo para esta proteína, 38\%, al igual que el de Sugawara y cols ${ }^{34}$.

La proteína con mayor expresión ha sido Lrp, con $64 \%$ de casos. Los trabajos inmunohistoquímicos que incluyen mayor número de pacientes se realizaron en muestras conservadas en parafina, y la expresión de Lrp fue del 45\%, 57\%, y 59\% respectivamente Un estudio sobre tejido congelado, pero con 36 pacientes, detectó nada menos que un $86 \%$ de expresión.

Un aspecto importante de nuestro estudio que lo diferencia de la mayoría de los publicados, es la determinación de la expresión simultánea de las tres MDR-proteínas en un mismo paciente. La presumible existencia e interacción de diferentes mecanismos de resistencia en vivo, justifican dicha importancia. Estudiada la muestra bajo este punto de vista, encontramos que el $83 \%$ de los pacientes expresaban proteínas, con $32 \%$ expresando una, 34\% expresando dos y $17 \%$ expresando las tres. Es decir el $51 \%$ de los pacientes expresaban más de una proteína.

Existen pocas publicaciones que hagan referencia a la simultaneidad de expresión de estas tres MDRproteínas en cáncer de pulmón. Zhou y cols ${ }^{35}$, en 30 pacientes con NSCLC, encuentran que alrededor de un $40 \%$ expresan a la vez Pgp, Mrp1 y Lrp, un porcentaje superior al $17 \%$ obtenido por nosotros, pero Zhou y cols emplean muestras conservadas en parafina y el número de casos es menor. En este estudio, aunque los autores no hacen mención expresa de ello, también es Lrp la proteína más expresada, con un $87 \%$ de casos. Nuestro estudio detecta una tendencia muy significativa de Pgp y Lrp a expresarse asociadas ( $41 \%$ de casos). Un resultado similar al obtenido por Volm y cols ${ }^{36}$, que en 87 pacientes refieren un 32\% de expresión simultánea de Pgp y Lrp.

Otros mecanismos de resistencia como las alteraciones en la glutation S-transferasa-тo las mutaciones de la p53, se han detectado a la vez que algunas MDR-proteínas, en cáncer de pulmón. Tal es el caso de la glutation S-transferasa-Tcon Pgp y Lrp, o de una p53 mutada con Mrp1 y Pgp. Esta tendencia a la asociación entre diferentes mecanismos de resistencia, pueden ser debidos a la existencia de factores comunes de regulación

Con respecto al grado de diferenciación histológico aunque sin alcanzar la significación, si hemos notado que la expresión de cualquiera de las proteínas tiende a ser mayor en los tumores bien diferenciados que en los pobremente diferenciados: 13/20 (65\%) vs $20 / 43(46,5 \%)$ para Pgp, $10 / 20(50 \%)$ vs $16 / 43$ $(37,2 \%)$ para Mrp1, y $14 / 20$ (70\%) vs 25/43 $(58,1 \%)$ para Lrp. Algunos autores si que encontraron que esta disminución de expresión conforme el tumor se desdiferencia era significativa.

Es en relación a la histología, donde se han publicado los resultados más discrepantes. Algunos estudios detectan una menor expresión de MDR-proteínas en los carcinomas indiferenciados de célula pequeña que en los de célula no pequeña, pero otros noo. Los pocos estudios de los revisados, que incluyen más de 30 pacientes con carcinomas indiferenciados de célula pequeña, revelan una expresión de Pgp que oscila entre el 12\% para Segawa y $\operatorname{cols}^{37}$ y el $26 \%$ de Hsia y cols ${ }^{38}$. Para Mrp1 la expresión oscila menos, entre un $31 \%$ y un $34 \%$ publicado por Hsia y $\operatorname{cols}^{36}$. En cuanto a Lrp los estudios son escasos y poco valorables, y según el método de detección empleado varían del $0 \%$ de expresión) hasta el $100 \%$ de Oguri y cols ${ }^{39}$. Nosotros dispusimos de solo 3 casos de carcinoma indiferenciado de célula pequeña, un número muy pequeño para extraer conclusiones válidas. Detectamos expresión solo en 1 caso $(33,3 \%)$ y este lo fue únicamente para Mrp1, solo con el AcMo Mrpm6 y en límite inferior de lo considerado positivo (10\% de células teñidas en la preparación).

Varios autores no encuentran relación entre los diferentes subtipos histológicos de carcinomas no cé- 
lula pequeña y la expresión de Pgp, Mrp1, o Lrp. En cambio, algunos describen una preferencial expresión de Pgp y fundamentalmente Mrp1 en carcinomas escamosos frente a adenocarcinomas, mientras otros encuentran precisamente lo contrario. Nosotros encontramos diferencias significativas en la expresión de Lrp y Mrp1 entre los diferentes tipos histológicos. Las más llamativas se dan en la expresión de Mrp1, la cual es muy baja en adenocarcinomas frente a indiferenciados de célula grande y escamosos, con porcentajes de $5,4 \%, 42,9 \%$ y $63,3 \%$ respectivamente. En la menor expresión de Mrp1 en adenocarcinomas coincidimos con algunos autores. En cambio, Lrp se expresa menos en los carcinomas escamosos que en adenocarcinomas y carcinomas indiferenciados de célula grande $(59,2 \% 78,4 \%$, $85,7 \%$ respectivamente), con lo que discrepamos aunque solo parcialmente con alguna publicación que encontraba mayor expresión de Lrp en adenocarcinomas y carcinomas escamosos que en indiferenciados de célula grande, y por lo que sus autores sugerían una relación entre Lrp y la diferenciación histológica tumoral. No encontramos diferencias en la expresión de Pgp.

Para los tipos histológicos más frecuentes, la proporción de pacientes que expresan alguna o varias proteínas en nuestro estudio es similar, con un $90 \%$ para los carcinomas escamosos, $81 \%$ para los adenocarcinomas, y $100 \%$ para los carcinomas indiferenciados de célula grande. Pero entre ellos difieren significativamente en el tipo y el número de proteínas que expresan. Los porcentajes de pacientes con carcinomas escamosos que expresan una, dos, o las tres proteínas a la vez son similares: $32,7 \%$ (16/49), $28,6 \%(14 / 49)$ y $28,6 \%(14 / 49)$ respectivamente. En cambio, en adenocarcinomas e indiferenciados de célula grande es mucho menos frecuente encontrar pacientes que expresen las tres proteínas simultáneamente: $5,4 \%(2 / 37)$ y $14,3 \%(1 / 7)$ respectivamente. Esto esta fundamentalmente relacionado con la baja expresión de Mrp1 en adenocarcinomas. Por este motivo, 14 de los 17 casos que expresan simultáneamente las tres proteínas, son carcinomas escamosos. Los adenocarcinomas expresan con frecuencia y de forma simultánea Pgp y Lrp (17 de 37 casos, 45,9\%) y también Lrp sola (10 de 37 casos, 27\%). En los carcinomas escamosos Pgp y Lrp aparecen juntas solo en 5 de los 49 casos $(10,2 \%)$, y Lrp sola en 6 casos (12,2\%). Los 7 carcinomas indiferenciados de célula grande no tienen predilección por expresar simultáneamente ninguna combinación de proteínas.

Hemos estudiado la tendencia de las MDR-proteínas a expresarse asociadas o no entre ellas, y en caso de asociarse con cual. Todas se presentan con más frecuencia asociadas a otras que solas. A destacar la relación entre Pgp y Lrp. Pgp se expresa en 44 casos, y de estos lo hace asociada en 41 (93\%), en todos ellos con Lrp (41 de 44 casos). La proporción de casos con expresión de Lrp que se asocian a Pgp es del 64\% (41/64). Esta tendencia de Pgp y Lrp a expresarse juntas, alcanza la significación estadística.

Hemos detectado alguna diferencia con respecto al sexo. En nuestro estudio, las mujeres expresan menos Mrp1 que los hombres. Esto puede deberse a que 9 de las 14 mujeres presentaban adenocarcinomas, tipo histológico que ha resultado expresar muy poco esta proteína. Ninguno de los trabajos revisados que hacen referencia al sexo, han encontrado relación entre este y la expresión de MDR-proteínas, pero solo uno de ellos estudiaba en concreto Mrp1. No encontramos diferencias entre sexos para Pgp y Lrp, ni tampoco en cuanto al número de proteínas expresadas simultáneamente.

El aspecto más importante del estudio de las MDR-proteínas en cáncer es lógicamente su implicación en la respuesta a la quimioterapia. Mientras que en algunos tipos de tumores hematológicos esta implicación está claramente establecida, en tumores sólidos, los datos son muy variados y poco concluyentes a este respecto ${ }^{29}$. Hasta la fecha, en cáncer de pulmón, no se puede excluir ni afirmar tal implicación. Nuestro análisis ulterior de éstos datos se dirigirá a la determinación del valor pronóstico de los mismos en relación a la respuesta quimioterápica y supervivencia ${ }^{40,41}$. Esperamos en un breve lapso de tiempo aportar resultados en relación a la resistencia a la quimioterapia y supervivencia global de ésta serie.

\section{Conclusiones}

De los resultados del presente estudio concluir que:

1. El cáncer de pulmón expresa con frecuencia MDR-proteínas.De las tres MDR-proteínas estudiadas, Pgp Mrp1 y Lrp, es Lrp la más frecuentemente expresada. 
2. Los adenocarcinomas expresan menos Mrp1 que el resto de los tipos histológicos. Los carcinomas escamosos expresan menos Lrp que los adenocarcinomas y carcinomas indiferenciados de célula grande.

3. Una proporción importante de pacientes expresan de forma simultánea más de una MDRproteína. Los carcinomas escamosos, son los que con más frecuencia expresan Pgp, Mrp1 y Lrp de forma simultánea. Pgp se expresa fundamentalmente asociada a Lrp.

\author{
Correspondencia: \\ Dr. M. Echenique Elizondo \\ Catedrático de Cirugía \\ Facultad de Medicina. UD San Sebastrián \\ Universidad del País Vasco \\ P. Dr. Begiristain, 105 \\ E-20014 San Sebastián (Guipúzcoa) \\ E-mail: gepecelm@sc.ehu.es
}

\section{Bibliografía}

1. Beck WT, Dalton WS. Mechanisms of Drug Resistance. Cancer, Principles and Practice of Oncology, 5th Edition. Editado por VT DeVita, S Hellman y SA Rosenberg. JB Lippincont Company, Philadelphia 1997: 498-512.

2. Chu E, DeVita VT. Principles of Cancer Management: Chemotherapy. Cancer, Principles and Practice of Oncology, 6th Edition. Editado por VT DeVita, S Hellman y SA Rosenberg. JB Lippincont Company, Philadelphia 2001: 289-386.

3. Goldie JH, Coldman AJ. A mathematic model for relating the drug sensitivity of tumors to their spontaneous mutation rate. Cancer treat Rep 1979; 63 1727-1731.

4. Skipper HE, Simpson-Herren L. Relationship Between Tumor Stem Cell Heterogeneity and Responsiveness to Chemotherapy. Important Advances in Oncology 1985. Editado por VT DeVita, S Hellman y SA Rosenberg. JB Lippincont Company, Philadelphia 1985: 63-77.

5. Shepherd FA, Carney DN. Treatment of NSCLC: Chemotherapy. Textbook of Lung Cancer. Editado por Heine $\mathrm{H}$ Hansen. Martín Dunitz Ltd, London 2000: 213-242.

6. Nishio K, Nakamura $\mathrm{T}$, Koh $\mathrm{Y}$ et al: Drug resístance in lung cancer. Current Opinion in Oncology 1999; 11: 109115 .

7. Miller AB, Hoogstraten B, Staquet M, Winkler A. Reporting results of cancer treatment. Cancer 1981; 47(1): 207 214.
8. Doyle LA. Mechanisms of Drug Resistance in Human Lung Cancer Cells. Semin Oncol 1993; 20: 326-337.

9. Tamm I, Schriever F, Dörken B. Apoptosis: implications of basic research for clinical oncology. Lancet Oncol 2001; 2: 33-42

10. Bradshaw D, Arceci RJ. Clinical Relevance of Transmembrane Drug Efflux as a Mechanism of Multidrug Resistance. J Clin Oncol 1998; 16(11): 3674-3690.

11. Gottesman MM, Fojo T, Bates SE. Multidrug Resistance In Cancer : Role Of Atp-Dependent Transporters. Nature Reviews Cancer 2002; 2: 48-58. .

12. Morrow ChS, Cowan KH. Mechanisms of Antineoplastic Drug Resistance. Cancer, Principles and Practice of Oncology, 4th Edition. Editado por VT DeVita, S Hellman y SA Rosenberg. JB Lippincont Company, Philadelphia 1993: 340-348.

13. Tan B, Piwnica-Worms D, Ratner L. Multidrug resistance transporters and modulation. Current Opinion in Oncology 2000; 12: 450-458.

14. Ishikawa T, Ali-Osman F. Glutathione-Associated CisDiammine-Dicloroplatinum (II) Metabolism And ATP-Depedent Efflux From Leukemia Cells. J Biol Chem 1993; 268: 20116-20125.

15. Plasencia C, Tarón M, Abad A, et al. Genes de quimiorresistencia. Manual de Oncología Clínica y Molecular. Editado por R. Rosell, A. Abad. M. Monzó. A. Barnadas. Arán Ediciones S.A. Madrid 2000: 145-159.

16. Dano K. Active outward transport of daunomycin in resistant Ehrlich ascitis tumor cells. Biochim Biophys Acta 1973; 323: 466-483.

17. Dalton WS. Overcoming the Multidrug-Resistant Phenotype. Cancer, Principles and Practice of Oncology. Editado por VT DeVita, S Hellman y SA Rosenberg. JB Lippincont Company, Philadelphia 1993. 2655-2666.

18. Borst P, Evers R, Kool M, et al. A Family of Drug Transporters: the Multidrug Resistance-Associated Proteins. J Natl Cancer Inst 2000, 92: 1295-1302.

19. Jedlitschky G, Leier I, Buchholz U, et al. ATP-dependent transport of glutathione S-conjugates by the multidrug resistance-associated protein. Cancer Res 1994; 54: 4833-4836.

20. Rappa G, Loico A, Flavell R, et al. Evidence that the multidrug resitance protein (MRP) functions as a co-transporter of glutathione and natural product toxins. Cancer Res 1997, 57:5232-5237.

21. Carney DN, Shepherd FA. Treatment of SCLC: Chemotherapy. Textbook of Lung Cancer. Editado por Heine H Hansen. Martín Dunitz Ltd, London 2000: 261-272.

22. Scheper RJ, Broxterman HJ, Scheffer GL, et al. Overexpression of a Mr 110.000 Vesicular Protein in Non-P-Glycoprotein-Mediated Multidrug Resistance. Cancer Res 1993; 53: 1475-1479.

23. Slovak ML, Pelkey Ho J, Cole SPC, et al. The LRP gene encoding a major vault protein associated with drug resistance maps proximal to MRP on cromosoma 16 : Evidence that chromosoma breakage plays a key role in MRP or LRP gene amplification. Cancer Res 1995; 55: 4214-4219. 
24. Scheffer GL, Wijngaard PLJ, Flens MJ, Izquierdo MA, et al. The drug resistance-related protein LRP is the human major vault protein. Nature Med 1995;1: 578-582.

25. Kedersha NL, Rome LH. Isolation and Characterization of a Novel Ribonucleoprotein Particle: Large Structures Contain a Single Species of Small RNA. J Cell Biol 1986; 103 : 699-709.

26. Boyle P, Gandini S, Gray N. Epidemiology of lung cancer: A century of great success and ignominious failure. Textbook of Lung Cancer. Editado por Heine H Hansen. Martín Dunitz Ltd, London 2000: 13-25.

27. Beer TW, Rowlands DC, Crocker J. Detection of the multidrug resistance marker P-glycoprotein by immunohistochemistry in malignant lung tumors. Thorax 1996;51(5): 526529.

28. Simon MF, Schindler M. Cell biological mechanisms of multidrug resistance in tumors. Proc. Natl. Acad. Sci. USA 1994; 91, Abril: 3497-3504.

29. Godstein LJ. MDR1 Gene Expression in Solid Tumours. Eur J Cancer 1996; 32A(6): 1039-1050.

30. World Health Organization. Histological typing of lung tumours. International Classification of tumours. $\mathrm{N}^{\circ} 1$, 2nd edn. World Health Organization. Geneva 1981.

31. UICC; International Union Against Cancer. TNM. Clasificación de los tumores malignos. Editado por L.H. Sobin y Ch. Wittekind. Versión en castellano de la $5^{\mathrm{a}}$ ed. Inglesa (1997). Pulso ediciones SA. Barcelona 2001.

32. Radosevich JA, Robinson PG, Rittmann-Grauer LS, et al. Inmunohistochemical analysis of pulmonary and pleural tumors with the monoclonal antibody HYB-612 directed againts the multidrug-resistance (MDR-1) gene product $\mathrm{P}$ glycoprotein. Tumor Biol 1989; 10: 252-257.

33. Scagliotti GV, Novello S, Selvaggi G. Multidrug resistance in non-small-cell lung cancer. Annals of Oncology 1999; 10 (Suppl. 5): S83-S86

34. Choi JH, Lim HY, Joo HJ, et al. Expression of multidrug resistance-associated protein $1, \mathrm{P}$-glycoprotein, and thymidylate synthase in gastric cancer patients treated with 5fluorouracil and doxorubicin-based adyuvant chemotherapy after curative resection. Br J Cancer 2002, 86(10): 1578-85.

35. Zhou J, Higashi K, Ueda Y, et al. Expression of multidrug resistance protein and messenger RNA correlate with $(99 m)$ Tc-MIBI imaging in patients with lung cancer. J Nucl Med 2001 Oct; 42 (10): 1476-83.

36. Volm M, Mattern J, Samsel B. Overexpression of P-glycoprotein and glutathione S-transferase-pi in resistant nonsmall-cell lung carcinomas of smokers. Br J Cancer 1991; 64(4): 700-704.

37. Segawa Y, Ohnoshi T, Hiraki S, et al. Immunohistochemical Detection of P-glycoprotein and Carcinoembryonic Antigen in Small Cell Lung Cancer: With Reference to Predictability of Response to Chemotherapy. Acta Med Okayama 1993; 47: 181-189

38. Hsia TC, Lin CC, Wang JJ, et al. Relationship Between Chemotherapy Response of Small Cell Lung Cancer and Pglycoprotein or Multidrug Resistance-Related Protein Expression. Lung 2002; 180(3): 173-179.

39. Oguri T, Isobe T, Fujitaka K, et al. Association between expression of the MRP3 gene and exposure to platinum drugs in lung cancer. Int J Cancer 2001 Aug 15; 93(4): 584-589.

40. Thomas H, Coley HM. Overcoming Multidrug Resistance in Cancer: An Update on the Clinical Strategy of Inhibiting P-Glycoprotein. Cancer control 2003; 10(2): 159-165.

41. Bates SE, Chen C, Robey R, et al: Reversal of multidrug resistance: lessons from clinical oncology. Novartis Foundation Symposium 243, 2002: 83-102. 